\title{
Atitudes linguísticas e o ensino de língua portuguesa: uma reflexão sociolinguística
}

\author{
Linguistic attitudes and the \\ teaching of portuguese language: \\ a sociolinguistic reflection
}

Juliana Bertucci Barbosa ${ }^{1}$

https://orcid.org/0000-0002-1510-633X

Rafaela Regina Ghessi ${ }^{2}$

https://orcid.org/0000-0003-3816-111X

\begin{abstract}
Resumo: O presente artigo tem como objetivo refletir sobre o ensino de língua portuguesa no Brasil, investigando atitudes linguísticas de professores de escolas da rede pública de Uberaba-MG, mediante o fenômeno variável de concordância verbal. Para isso, serão feitas algumas reflexões a respeito da Teoria da Variação e Mudança Linguística (WEINREICH; LABOV; HERZOG, 2006) e uma revisão teórica acerca dos conceitos de atitudes e avaliações linguísticas (LABOV, 2008 [1972]; LAMBERT, 1967). Com relação à coleta do corpus, foi aplicado um questionário a onze professores, de modo a analisar sua posição diante do fenômeno da concordância e da variação linguística. A partir das respostas foi possível evidenciar que o ensino de língua portuguesa está distante de um ensino reflexivo e de uma pedagogia da variação linguística (FARACO, 2007).
\end{abstract}

Palavras-chave: Atitudes linguísticas; Fenômeno variável; Pedagogia da Variação Linguística.

\footnotetext{
${ }^{1}$ Universidade Federal do Triângulo Mineiro. E-mail: julianabertucci@gmail.com

${ }^{2}$ Universidade Estadual Paulista. E-mail: rafaela.rghessi@gmail.com
} 
Abstract: This article aims to reflect on the teaching of Portuguese language in Brazil, investigating the linguistic attitudes of teachers of public schools in Uberaba-MG, through the variable phenomenon of verbal agreement. For this, some reflections on the Theory of Variation and Linguistic Change (WEINREICH, LABOV; HERZOG, 2006) and a theoretical revision on the concepts of attitudes and linguistic evaluations will be made (LABOV, 2008 [1972] and LAMBERT, 1967). With regard to the collection of the corpus, a questionnaire was applied to eleven teachers, in order to analyze their position in the face of the phenomenon of agreement and linguistic variation. From the answers it was possible to show that the Portuguese language teaching is far from reflective teaching and a pedagogy of linguistic variation (FARACO, 2007).

Keywords: Linguistic attitudes; Variable phenomenon; Pedagogy of linguistic variation.

\section{Introdução}

A Sociolinguística é uma área da Linguística que se dedica ao estudo da relação entre língua que falamos e sociedade em que vivemos. Seu desenvolvimento pautou-se, principalmente, na heterogeneidade linguística inerente e sistemática, uma vez que é postulado que toda língua natural é marcada pela variação. A variação faz parte, portanto, do funcionamento da língua, de modo que proporciona ao falante escolha de diversas formas, também conhecidas como "variantes", de expressar o mesmo significado referencial. É o que podemos observar com o fenômeno de Concordância Verbal (CV) de $3^{\circ}$ pessoa do plural, em que para este fenômeno estão em evidência duas variantes, ausência de marcação de plural nos verbos (Os meninos fala $\varnothing$ ) e a presença de marcação de plural nos verbos (Os meninos falam).

No entanto, uma das formas para a realização de um mesmo fenômeno pode possuir um valor sociolinguístico e uma maneira de desqualificar o falante da língua, como é possível observar com a CV, de modo que muitos estudos (cf. VIEIRA, 1995; SCHERRE e NARO, 2006; LUCCHESI, BAXTER e SILVA, 2009, OLIVEIRA, 2010; entre outros) demonstraram que quem faz a marcação de número se coloca em uma posição superior e prestigiada e quem não o faz acaba sendo estigmatizado. De acordo com Scherre (2005):

Quem deixa de fazer concordância de número é normalmente chamado de burro, ignorante, porque, afirma-se, "não saber falar". Somos então às vezes inteligentes e às vezes burros? Somos "variavelmente" inteligentes? Repito: a variação da concordância de número no português brasileiro está seguramente instalada na língua falada [...]. (SCHERRE, 2005, p.20). 
A reação de julgar o outro através de sua fala é chamada de avaliação linguística. A avaliação e as atitudes linguísticas são, de acordo com Cyranka (2007, p.20), formas de expressar o que os falantes pensam, sentem e como reagem sendo expostos aos estímulos linguísticos que lhes são apresentados.

As atitudes e avaliações diante um fenômeno superavaliado, como a CV, são vistas pelos professores que confundem o ensino de Língua Portuguesa com o ensino de uma norma padronizada e homogênea. O desconhecimento da pluralidade da língua faz com que muitos professores considerem algumas estruturas ou expressões, nos textos dos alunos, como "erradas" ou não pertencentes a idealizada "norma-padrão". Esse tipo de avaliação do professor cria estereótipos linguísticos, estigmatizando e/ou excluindo a variedade do aluno. O tema da avaliação linguística deve ser tratado no contexto escolar, pois suscita um processo de construção de julgamentos subjetivos dos falantes em relação a sua língua e a do seu interlocutor.

Partindo dos pressupostos da teoria da Variação e Mudança Linguística (WEINREICH; LABOV; HERZOG, 2006; LABOV, 2008[1972]), o presente artigo tem como objetivo refletir sobre o ensino de língua portuguesa no Brasil, investigando atitudes linguísticas de professores de escolas da rede pública de Uberaba-MG, mediante o fenômeno variável de concordância verbal $(\mathrm{CV})$ de $3^{\circ}$ pessoa do plural. A construção do corpus foi feita com questionários aos professores, de modo a analisar sua posição diante do fenômeno da concordância e da variação linguística. A partir das respostas dadas pelos professores é possível evidenciar que o ensino de língua portuguesa está distante de um ensino reflexivo e de uma pedagogia da variação linguística ${ }^{3}$ (FARACO, 2007), ainda que seja possível observar algumas mudanças de atitudes desses professores.

Dessa forma, é de suma importância trabalhos como esse para a Sociolinguística, pois estimula uma nova atitude do professor de língua materna, visando um ensino que considera o aluno como um indivíduo pensante e ativo e não mais aquele que "não sabe português". Paulo Freire, em todas as suas discussões sobre a pedagogia libertadora, traz à reflexão a necessidade de dar voz aos alunos, de modo que ouvi-los significa "[...] captar a linguagem deles e, necessariamente, seus temas, que vêm através de suas palavras e de sua sintaxe. É claro,

\footnotetext{
3 O termo "pedagogia da variação linguística", cunhado por Faraco (2007), vai ao encontro do o que Bortoni-Ricardo (2004) denomina de "Sociolinguística Educacional", no qual também propõe reflexões sociolinguísticas que contribuem para o ensino/aprendizagem de língua portuguesa no Brasil e que, por sua vez, dialoga com o que Erickson (1987) apontava como "pedagogia culturalmente sensível".
} 
exatamente porque a linguagem é um problema de classe social"' (FREIRE, 2011, p.245).

\title{
1. Pressupostos teóricos
}

\subsection{Reflexões sobre a sociolinguística}

A Sociolinguística tornou-se uma ciência autônoma e interdisciplinar em meados dos séculos XX. Seu desenvolvimento pautou-se no relativismo cultural e na heterogeneidade ordenada do sistema linguístico. De acordo com Bortoni-Ricardo (2014):

\begin{abstract}
Segundo o relativismo cultural, nenhuma língua ou variedade de língua, em uso em comunidades de fala, deveria ser considerada inferior ou subdesenvolvida, não obstante o nível da tecnologia ocidental que aquela comunidade tenha avançado. Já a heterogeneidade inerente e ordenada, que está na raiz da Sociolinguística, postula que toda língua natural é marcada pela variação, a qual não é assistemática. Pelo contrário, os recursos da variação, que toda língua natural oferece, estão sistematicamente organizados em sua estrutura e contribuem para tornar a comunicação entre os falantes mais produtiva e adequada. (BORTONIRICARDO, 2014, p.157).
\end{abstract}

Weinreich, Labov e Herzog (2006 [1968]), no livro Fundamentos empíricos para uma teoria da mudança linguística, criticam o conceito de língua que foi proposto por Saussure (2006) no Curso de Linguística Geral, pois sua teoria não supunha em nada conhecimentos históricos, mas apenas o bom funcionamento da língua. De acordo com os autores, Saussure não caracterizou de forma satisfatória a língua como um fato social, além de ter estabelecido a completa homogeneidade do código linguístico como pré-condição para a análise linguística. Ao contrário dos postulados de Saussure, os autores Weinreich, Labov e Herzog (2006) entendem que a variabilidade caracteriza o uso normal da língua e é importante para entender os mecanismos de seu funcionamento, assim como a mudança linguística. A mudança linguística e a heterogeneidade se tornam essenciais para a existência de uma língua, sendo dois fatores indissolúveis, pois, como aponta Conde Silvestre (2007, p.31), “o desenvolvimento de uma mudança implica historicamente a existência de heterogeneidade na comunidade de fala". ${ }^{4}$

\footnotetext{
${ }^{4}$ Tradução própria. Texto original: "el desarrollo de un cambio implica general e historicamente la existencia de heterogeneidad sincrónica en la comunidade de habla que se trate."
} 
Assim, podemos dizer que a Sociolinguística tem como principal objeto de estudo a língua em uso, aquela utilizada pelos falantes nas mais diversas situações de comunicação, seja ela realizada na fala ou na escrita. Os estudiosos dessa área observam, portanto, a língua real que, assim como todas as línguas naturais do mundo, exibe variações e se constitui por um conjunto de variedades, não existindo predomínio linguístico entre as línguas e nem entre as variedades de uma mesma língua (MARINE e BARBOSA, 2016, p.188). A Sociolinguística legitima qualquer variedade linguística e não somente a "padrão". De acordo com Milroy (2011):

\footnotetext{
O estabelecimento da ideia de uma variedade padrão, a difusão de conhecimento dessa variedade, sua codificação em compêndios gramaticais e dicionários largamente usados e sua promoção num amplo espectro de funções- tudo isso leva à desvalorização das outras variedades. A forma padrão se torna a forma legítima, e as outras formas se tornam, na mente do povo, ilegítimas. (MILROY, 2011, p.76).
}

Apesar de todas as evidencias proporcionadas pela Sociolinguística em relação a heterogeneidade da língua e sua tentativa de legitimar todas as variedades, a sociedade se orienta, de acordo com Faraco (2011, p.266), por um imaginário segundo a qual há, na língua, princípios claros e indiscutíveis de correção, imaginário que resiste aos fatos e aos argumentos lógicos-racionais. Dessa forma, os falantes sentem-se autorizados a censurar o comportamento linguístico dos outros, que acaba conferindo a algumas variedades prestígio e a outros estigmas. De acordo com Gnerre (1998, p. 6) "uma variedade linguística 'vale' o que 'valem' na sociedade os seus falantes".

Sendo a escola um ambiente que trata sobre a língua materna, acredita-se que todos esses aspectos mencionados acima constituem a realidade da sala de aula. Os professores devem estar preparados para lidar com a pluralidade linguística, se não terão atitudes estereotipadas em relação a variedade linguística do aluno, desconsiderando uma história e uma identidade. A Sociolinguística tem também o objetivo de contribuir com o ensino de língua portuguesa, uma vez que é possível desenvolver um ensino voltado à reflexão dos fenômenos linguísticos, sem considerar "erradas" as variedades que os alunos trazem de seu contexto social e levam ao ambiente escolar.

\subsection{Variação e ensino}

A língua não é a gramática tradicional e a variação linguística não é apenas mais um 
conteúdo do livro didático, mas uma postura em relação à língua e à forma como ela precisa ser ensinada dentro das escolas (CARDOSO e COBUCCI, 2014, p. 99). Sem dúvida, a pedagogia da variação linguística e a sociolinguística educacional têm um importante papel na investigação relativa ao trabalho escolar com a linguagem, trazendo a possibilidade de se proceder a uma revisão da tarefa da escola em levar os alunos a desenvolverem sua competência comunicativa $^{5}$ tanto na modalidade falada como na escrita. Para isso, é proposto um ensino voltado à reflexão dos fenômenos linguísticos, no qual os professores não vão ensinar os alunos a falarem o português, mas irão ampliar os conhecimentos com que chegam à escola. De acordo com Camacho (2001):

\begin{abstract}
As variedades são alternativas e podem conviver harmoniosamente na sala de aula, cabendo ao professor o bom senso de discriminá-las adequadamente, fornecendo ao aluno as chaves para perceber as diferenças de valor social entre elas e, depois, saber tirar vantagem dessa habilidade, selecionando a mais adequada conforme as exigências das circunstâncias do intercurso verbal. (CAMACHO, 2001, p.72).
\end{abstract}

Como aponta Faraco (2008), os linguistas não são contrários ao ensino das variedades cultas e situam essas variedades no contexto das práticas socioculturais da escrita, defendendo, em consequência, uma prática pedagógica centrada no letramento no sentido amplo e não apenas em formas linguísticas.

\begin{abstract}
A crítica à gramatiquice e ao normativismo não significa, como pensam alguns desavisados, o abandono da reflexão gramatical e do ensino da norma culta/comum/standard. Refletir sobre a estrutura da língua e sobre seu funcionamento social é atividade auxiliar indispensável para o domínio fluente da fala e da escrita. E conhecer a norma culta/comum/standard é parte integrante do amadurecimento das nossas competências linguístico-culturais, em especial as que estão relacionadas à cultura escrita. O lema aqui pode ser: reflexão gramatical sem gramatiquice e estudo da norma culta/comum/standard sem normativismo. (FARACO, 2008, p.157).
\end{abstract}

O equívoco aparece quando se distinguem entre: as variedades cultas (designadas pela

\footnotetext{
${ }^{5}$ Entendemos competência comunicativa como um conceito que inclui "[...] não só as regras que presidem à formação das sentenças, mas também as normas sociais e culturais que definem a adequação da fala" (BORTONI-RICARDO, 2004, p.73). A competência comunicativa de um falante lhe permite saber o que falar e como falar com quaisquer interlocutores e em quaisquer situações de comunicações, sendo esta a noção de "adequação" proposta por Dell Hymes e retomada por Bortoni-Ricardo (2004).
} 
expressão genérica norma culta), norma-padrão e norma gramatical. Norma culta/comum/standard (plano da realização) é a "variedade que os letrados usam correntemente em suas práticas mais monitoradas de fala e escrita" (FARACO, 2008, p. 73). Nas palavras de Faraco (2008):

\begin{abstract}
Enquanto a norma culta é a expressão viva de certos segmentos sociais em determinadas situações, a norma- padrão é uma codificação relativamente abstrata, uma baliza extraída do uso real para servir de referência, em sociedades marcadas por acentuada dialetação, a projetos políticos de uniformização linguística. (FARACO, 2008, p 73).
\end{abstract}

Por fim, a norma gramatical é a idealização por filólogos renomados e é codificada em manuais tradicionais, como gramáticas e dicionários, contemplando o que seria "o conjunto de fenômenos apresentados como cultos/comuns/standard por esses gramáticos" (FARACO, 2008, p. 81). Vale salientar que o prestígio da norma culta é de natureza puramente sociocultural e esse prestígio que justifica seu ensino. Linguisticamente não é superior nem inferior as demais (FARACO, 2011, p.261).

É evidente que o ensino voltado à reflexão gramatical tem a língua como um fato social e heterogêneo, porém levar essa concepção à escola não é uma tarefa fácil, uma vez que o normativismo e as regras gramaticais são parte de um conjunto de conceitos, atitudes e valores autoritários, marcados por uma sociedade conservadora e excludente. Partindo dessas reflexões, o início de uma "pedagogia da variação linguística" pauta-se, primeiramente, no livramento de alguns mitos e crenças que permeiam a língua, como por exemplo, o de que existe uma única variedade da língua portuguesa que é "correta". De acordo com Faraco (2007):

\footnotetext{
[...] nosso grande desafio, neste início de século e milênio, é reunir esforços para construir uma pedagogia da variação linguística que não escamoteie a realidade linguística do país (reconheça-o como multilíngue e dê destaque crítica à variação social do português); não dê tratamento anedótico ou estereotipado aos fenômenos da variação; localize adequadamente os fatos da norma culta/comum/standard no quadro amplo da variação e no contexto das práticas sociais que a pressupõem; abandone criticamente o cultivo da norma padrão; estimule a percepção do potencial estilístico e retórico dos fenômenos da variação. (FARACO, 2007, p.46-47).
}

Deve-se partir do pressuposto de que a língua varia de acordo com as situações de comunicação, sendo assim, não existe variedade certa, mas uma variante adequada para cada situação. Sobre isso, orienta os Parâmetros Curriculares Nacionais de Língua Portuguesa (PCNs) 
do terceiro e quarto ciclos:

\begin{abstract}
No ensino-aprendizagem de diferentes padrões de fala e escrita, o que se almeja não é levar os alunos a falarem certo, mas permitir-lhes a escolha da forma de fala a utilizar, considerando as características e condições do contexto de produção, ou seja, é saber adequar os recursos expressivos, a variedade de língua e o estilo às diferentes situações comunicativas: saber coordenar satisfatoriamente o que fala ou escreve e como fazê-lo saber que modo de expressão é pertinente em função de sua intenção enunciativa... a questão não é de erro, mas de adequação às circunstâncias de uso, de utilização adequada de linguagem. (BRASIL, 1998, p.31).
\end{abstract}

A escola não pode ignorar as diferenças sociolinguísticas, deve-se usá-las para que os alunos reflitam sobre o distanciamento da variedade que aprenderam em casa com as variedades cultas, que aprendem na escola. Assim, o aluno precisa ter consciência de que a língua varia e sofre mudanças, cujas causas se relacionam com aspectos sociais, econômicos, históricos, etc. De acordo com Luft (2009, p.69), "todas as variedades da língua são valores positivos. Não será negando-as, perseguindo-as, humilhando quem as usa, que se fará um trabalho produtivo no ensino".

Se a escola continuar negando o caráter sócio-histórico da variação ela continuará se defrontando com resultados negativos em relação ao desenvolvimento da competência do uso da norma culta pelos alunos, pois, assim, os alunos que possuem uma variedade diferente da de prestígio não se sentirão capazes de adquirir a competência de uso dessa variedade. A variedade do aluno não deve ser motivo de exclusão e nem a escola deve ser ambiente de fortalecimento de preconceitos linguísticos. De acordo com Bortoni-Ricardo $(1985$, p.92) a avaliação positiva das variedades prestigiadas em contrapartida às não-prestigiadas pode representar, para o falante, a perda da percepção da sua integridade pessoal ou a identidade de grupo. A necessidade de uma nova pedagogia de ensino de língua materna pauta-se em um trabalho sem prejuízo para os valores sociais dos alunos, que só pode ser respondido com o apoio do que Erickson (1987) denominou como "pedagogia culturalmente sensível". Bortoni-Ricardo (2005) assim explica essa proposta:

É objetivo da pedagogia culturalmente sensível criar em sala de aula ambientes de aprendizagem onde se desenvolvem padrões de participação social, modos de falar e rotinas comunicativas presentes na cultura dos alunos. Tal ajustamento nos processos interacionais é facilitador da transmissão do conhecimento, na medida em que se ativam nos educandos processos cognitivos associados aos processos sociais que lhes são familiares. (BORTONI-RICARDO, 2005, p.128). 
Para visualizar as reflexões sobre essa pedagogia inovadora, será apresentada a pesquisa-ação Cyranka (2015), no qual propõe uma reflexão de diferenças dialetais com alunos falantes rurbanos ${ }^{6}$, entre 13 e 17 anos, em uma escola pública municipal de Juiz de Fora (MG). A discussão retratou a existência de outros países que também possuem a língua portuguesa como a língua oficial. De acordo com a pesquisadora, o objetivo era chegar a diferenças dialetais do português "abrindo caminho para a reflexão sobre a legitimidade delas, de modo a construir laços de confiança entre a cultura da escola e as culturas não valorizadas das quais era representantes" (p.39).

A reflexão dessas diferenças dialetais é trabalhada, pela autora, com o viés de "adequação", de valores relativos, e não atribuindo valores absolutos de "certo" ou "errado". Como pode ser visto no exemplo a seguir:

\author{
Aluna: Fala com um jeito de funkeiro. \\ Professora: O que é igual a funkeiro? \\ Giovanne: Palavras de funk, gírias como "tá ligado", "tipo assim." \\ Gustavo: O Mc Guimê gosta de falar "tá ligado". \\ Professora: Esse jeito de falar é mais formal ou menos formal? \\ David: Menos formal. \\ David: Tipo assim, se você for em um tribunal de justiça e falar com o juiz \\ "tá ligado", não pode né!?. (CYRANKA, 2015, p. 40).
}

Este trabalho que foi feito por Cyranka (2015) apresentou resultados animadores, que de acordo com ela, os alunos passaram a compreender o significado do ensino de língua portuguesa, "não mais para negar o que já sabe, mas para ampliar sua competência comunicativa, abrindo-lhes caminhos para sua inserção social, construindo a própria autonomia" (p.51). De acordo com Faraco (2015), uma das práticas pedagógicas indispensáveis para o ensino/aprendizagem da expressão culta é precisamente despertar a consciência dos alunos para a variação linguística.

A postura em relação a linguagem observada na pesquisa de Cyranka (2015) deve estar presente no ensino da concordância de número. Não basta imprimir as regras gramaticais a

\footnotetext{
${ }^{6}$ Termo utilizado por Bortoni-Ricardo (2004), que propõe um contínuo para evitar o risco de delimitar fronteiras rígidas entre as variedades linguísticas. A variedade rurbana estaria em um contínuo intermediário entre as variedades rurais e as variedades urbanas.
} 
respeito da concordância de número, é necessário observar como esses elementos da língua são de fato empregados em gêneros textuais. Para um ensino eficiente da concordância de número "é importante conhecer bem nossa realidade sociolinguística, com todas as possibilidades de variação, pois, assim, teremos melhores condições de selecionar gêneros textuais a serem trabalhados- tantos os falados como os escritos" (CARDOSO e COBUCCI, 2014, p.101).

Vale enfatizar que a pedagogia culturalmente sensível não desconsidera o ensino da gramática normativa, mas a utiliza de forma diferente: refletindo os usos nos contextos reais de comunicação. A utilização das regras padronizadas deve ter seu lugar assegurado no processo de ensino de língua, pois como aborda Cyranka (2013), trabalhar em sala de aula com as estruturas mais prestigiadas é importante, porque amplia o uso linguístico dos alunos para além daqueles que estão presente no seu cotidiano, sem demonstrar preconceito ou desprezo pela variedade de fala que o aluno já tem e que faz parte da sua história e identidade.

Esse estudo de Cyranka (2015) foi uma amostra de outras pesquisas que acontecem dentro de sala de aula amparada a uma pedagogia da variação linguística, que amplia o domínio de uso da língua portuguesa dos alunos considerando os usos reais. As pesquisas sociolinguísticas no âmbito escolar demonstram que é possível uma prática fundamentada na valorização das diversas variedades linguísticas e dos diversos usos do português brasileiro. A ampliação do conhecimento do aluno e o uso de seu idioma por meio do reconhecimento e do uso efetivo das variedades linguísticas "é fundamental para garantir seus direitos e um lugar na sociedade em que faz parte" (CYRANKA, 2013, p. 89).

\subsection{Avaliação e atitudes linguísticas}

O conhecimento e o discurso acerca do conceito de avaliação e atitudes linguísticas mostram-se essenciais ao tratar-se do ensino de língua portuguesa, visto que a construção de julgamentos subjetivos de um falante em relação a sua própria língua ou a do seu interlocutor possuem impactos identitários e afeta como os falantes pensam sobre sua língua.

A atitude linguística não pode ser compreendida sem primeiro entender as crenças e ideologias linguísticas que perpassam o imaginário de uma comunidade, pois o julgamento linguístico é fruto dessas crenças. As crenças são um construto do contexto em que está inserido. Segundo Barcelos (2007, p.114), as crenças "incorporam as perspectivas sociais, pois nascem no contexto de interação e na relação com os grupos sociais".

A postura coerciva que está presente nas escolas advém de um modelo medieval de ensino de língua que chegou ao Brasil no século XVI, favorecido por características excludentes 
e de uniformidade linguística (FARACO, 2008, p.148). A pureza da língua portuguesa deveria ser mantida, pois só assim preservaríamos a língua do colonizador, os portugueses, seus legítimos e únicos proprietários. Os brasileiros sempre foram condicionados por um imaginário que os fazem querer aproximar dos portugueses e abandonarem sua identidade. De acordo com Faraco (2008):

Como resultado da consolidação desse modelo entre nós, o normativismo e a gramatiquice se entranharam em nossos modos de conceber a língua. É comum, por exemplo, as pessoas que tiveram experiência de escolarização, dizerem que ninguém fala bem o português no Brasil; que os brasileiros falam errado. (FARACO, 2008, p.148).

Em consequência, a escola continua ensinando um estado de língua que não existe mais e continua reforçando valores absolutos de "certo" e "errado. Portanto, o estudo sobre o ensino de língua portuguesa deve pautar-se, como aponta Cyranka (2007, p.25) na "posição em que os professores e os alunos colocam os objetos (língua, linguagem, variação e aprendizagem linguística) dentro da dimensão avaliativa, posição essa que, em última instância, leva à atitude deles em relação a esses objetos". Assim, é permitido dizer que a atitude linguística é um resultado de convicções que o falante tem sobre a língua e outros elementos relacionados a ela, como a variação. Vale salientar que as crenças são mutáveis (SANTOS, 1996) e se professor propiciar discussões sobre a pluralidade linguística, ou seja, pautar-se em uma pedagogia da variação linguística, essas crenças podem ser (re)significadas, alterando, portanto, as crenças dos alunos e caminhando para a mudança de um cenário linguístico de diversidades.

De acordo com Labov (2008 [1972]) foi com o trabalho de Lambert (1967), com a técnica dos "falsos pares" ("matched guises"), que houve um progresso na mensuração das reações sociais inconscientes à linguagem:

\footnotetext{
A técnica dos "falsos pares" desenvolvida por Lambert (1967) é o instrumento básico agora amplamente utilizado para o estudo de reações subjetivas à linguagem. O princípio essencial que emerge do trabalho de Lambert é o de que existe um conjunto uniforme de atitudes frente à linguagem que são compartilhadas por quase todos os membros da comunidade de fala, seja no uso de uma forma estigmatizada ou prestigiada da língua em questão. Essas atitudes não emergem de forma sistemática se a pessoa for questionada diretamente sobre os dialetos; mas se ela fizer dois conjuntos de julgamentos de personalidade sobre o mesmo falante usando duas formas diferentes da língua, e se não perceber que é o mesmo falante, suas avaliações subjetivas da língua emergirão como diferenças nas duas pontuaçõ̃es. (LABOV, 2008 [1972], p. 176).
} 
Lambert (1967), em seu trabalho com falantes bilíngues, definiu atitude como "a manifestação de preferências e convenções sociais acerca do status e prestígio de seus usuários". Além disso, postulou que a atitude é composta por três componentes: cognitivo, afetivo e conativo. O componente cognitivo diz respeito às crenças que o falante tem em relação a um objeto social referido; o componente afetivo refere-se às emoções do sujeito, à dimensão da valoração, e o terceiro, o componente conativo, refere-se à conduta que o falante tem diante do objeto social.

A avaliação faz parte da problemática dos princípios empíricos da Teoria da Variação e Mudança Linguística de Weinreich, Labov e Herzog (2006), de modo que os autores discutem a importância da avaliação na mudança linguística:

[...] o estudo do problema da avaliação na mudança linguística é um aspecto essencial da pesquisa que conduz a uma explicação da mudança. Não é difícil ver como traços de personalidade inconscientemente atribuídos a falantes de um dado subsistema determinariam a significação social da alternância para esse subsistema e assim seu desenvolvimento ou obsolescência como um todo. (WEINREICH, LABOV e HERZOG, 2006, p. 103).

De acordo com Labov (2008 [1972]) "Nem todas as mudanças linguísticas recebem avaliação social explícita ou sequer reconhecimento. Algumas parecem ficar muito abaixo do nível das reações sociais explícitas" (p.354). Dessa forma, o autor coloca em um continuum a avaliação que se faz de um fenômeno linguístico, que são chamados de indicadores, marcadores e estereótipos. Os indicadores e os marcadores, a grosso modo, não possuem muita força avaliativa, diferente dos estereótipos, que "são formas socialmente marcadas, rotuladas enfaticamente pela sociedade" (LABOV, 2008 [1972], p. 360). De acordo com Botassini (2015):

\footnotetext{
Esse rótulo que se impõe sobre determinados grupos linguísticos está pautado nos julgamentos sobre as pessoas, nas crenças que o indivíduo carrega a respeito de um traço linguístico, nos conhecimentos sobre um grupo e sua cultura, nos preconceitos em relação a língua e aos falantes dessa língua. (BOTASSINI, 2015, p.125).
}

As variantes linguísticas que possuem maior força avaliativa são mais facilmente identificadas. A CV, por exemplo, é um fenômeno superavaliado socialmente no Brasil, de modo que a variante explícita de plural é a variante de prestígio e a variante zero de plural, quando percebida, é julgada pela tradição e pelos falantes como índice de não saber falar português 
(SCHERRE e NARO, 2006, p.108). Os estudos de atitudes linguísticas revelam que o falante é percebido de forma positiva quando utiliza uma língua ou variedade linguística de prestígio (AMARAL, 1989, p.25-26), enquanto que os falantes constroem atitudes estereotipadas sobre língua e variedades que são marginalizadas. Sobre isso, Milroy (2011) argumenta:

\begin{abstract}
Com efeito, não é difícil argumentar que as variedades de língua realmente não têm prestígio em si mesmas: tais variedades adquirem prestígio quando seus falantes têm prestígio elevado, porque o prestígio é atribuído pelos seres humanos a determinados grupos sociais e a objetos inanimados ou abstratos $[\ldots]$ O prestígio atribuído às variedades linguísticas (por metonímia) é indexador e está envolvido na vida social dos falantes. (MILROY, 2011, p.53).
\end{abstract}

Dentre as investigações no campo das avaliações e atitudes linguísticas, o estudo de Labov (2008[1972]) com os falantes de inglês da Ilha de Martha's Vineyard, teve grande destaque. O estudo dos dados mostra que a alta centralização de (ay) e (aw) está intimamente correlacionada a expressões de grande resistência às incursões dos veranistas, exprimindo o significado social dos ditongos centralizados. A ilha possui, pela pressão econômica, a dependência do turismo e, portanto, a crescente dependência em relação ao turismo de verão atua como uma ameaça à independência pessoal deles. Aqueles que se identificam com a ilha e são avessos aos turistas centralizam mais os ditongos /ay/ e /aw/ para preservarem sua marca de identidade, no entanto, aqueles que reagem positivamente ao turismo apresentam em menor escala essa centralização ou então não apresentam (LABOV, 2008 [1972], p. 57).

As atitudes linguísticas relacionam-se, portanto, com o problema da avaliação, que busca compreender os correlatos subjetivos das mudanças linguísticas em curso. Estudos que estão nesse âmbito promovem caminhos para conhecer como as crenças, atitudes e avaliações linguísticas interferem no processo de constituição da identidade de uma comunidade.

\title{
2 Procedimentos metodológicos
}

Primeiramente foi realizada uma revisão bibliográfica sobre a Teoria da Variação e Mudança Linguística (WEINREICH, LABOV e HERZOG, 2006; LABOV, 2008[1972]) e sobre os conceitos de Avaliação e Atitudes linguísticas, refletindo seu impacto no ensino/aprendizagem de língua portuguesa. Em seguida, foram recolhidas algumas informações de um corpus construído por questionários aplicados a professores atuantes na rede pública da cidade de Uberaba, Minas Gerais. Participaram dessa pesquisa onze professores de Língua Portuguesa. 
Como essa pesquisa envolve seres humanos, antes de recolher os dados, a proposta de trabalho foi submetida ao Comitê de Ética em Pesquisa (CEP), subordinado a uma comissão Nacional de Ética em Pesquisa (CONEP), vinculada ao Ministério da Saúde.

Com relação à coleta do corpus, o teste foi aplicado em três escolas públicas da cidade de Uberaba entre os dias 17 e 28 de abril de 2017. Os professores responderam as questões na própria escola, para evitar a intervenção de terceiros. Cabe destacar que, intencionalmente, o teste não continha questões especificamente referentes a CV com o intuito de não interferirmos nas respostas e deixar que os próprios professores se Ihe chamassem a atenção, dissertassem sobre esse fenômeno variável (presente nos fragmentos).

O questionário foi composto por questões dissertativas, cujo objetivo era verificar as atitudes dos professores em relação a variação linguística e ao fenômeno variável de concordância verbal de $3^{\circ}$ pessoa do plural. O questionário foi construído contendo duas partes: (1) levantamento de informações relacionadas aos perfis sociais e formação docente; (2) questões sobre a língua, buscando selecionar as atitudes linguísticas dos professores.

Para este trabalho, analisamos de uma forma geral as respostas dos professores referentes a dois fragmentos com graus de monitoramento em relação à norma culta diferentes: um fragmento mais próximo da norma culta outro mais distante. O segundo fragmento, portanto, foi o que apresentou características do que se considera fora da norma culta (com ausências de concordâncias verbais, poucos mecanismos de coesão, etc.), cujo objetivo é o de que quando o professor respondesse ao teste de atitudes pudéssemos observar sua reação no que se refere às convenções e aos padrões institucionalizados. Seguem abaixo os fragmentos:

(I) Eles permaneceram lá por 45 dias e passaram por muitos lugares, muitas cidades e conheceram um pouco da cultura de cada um. É claro que eles perceberam que muitas coisas são diferentes dos costumes que temos aqui no Brasil, mas, mesmo assim ficaram encantados com tudo o que puderam presenciar naqueles lugares.

(II) Chegando em seu destino, desceram e prosseguiu até a casa da amiga. Chegando lá todos sentou e conversou, até que a mãe de sua amiga lhe ofereceram para eles almoçar. Todos almoçou, lavou às louças, então decidiram ir todos para a casa.

Os professores, em uma das questões, formularam impressões, delineando o perfil social dos autores dos dois fragmentos. A escala de diferencial semântico (OSGOOD, SUCl e TANNENBAUM, 1957) utilizada neste estudo foi composta, representando a dimensão de 
poder, pelos adjetivos competente, inteligente, rico, analfabeto, burro, caipira e desempregado; para a de solidariedade, boa pessoa, honesto, bonito e confiante. Ao lado de cada adjetivo estão alinhadas horizontalmente as notas variando de 7 a 1. De acordo com Chambers (1995):

\begin{abstract}
Uma dimensão denominada 'orientação para o prestígio' (RYAN, 1979, p. 151) inclui qualidades que têm a ver com inteligência, educação, ambição, riqueza, sucesso e conquista, e os sujeitos atribuem as avaliações mais altas para essas qualidades aos falantes da variedade padrão. A outra dimensão, 'orientação para a solidariedade', inclui qualidades, tais como gentileza, amabilidade, amizade, bondade e confiança, e os sujeitos atribuem as avaliações mais altas para essas qualidades aos falantes regionais ou de outras variedades não-padrão. (CHAMBERS, 1995 apud CYRANKA, 2007, p.35).
\end{abstract}

\title{
3 Análise dos dados
}

\subsection{Perfil dos professores}

O quadro a seguir traz um breve perfil dos professores envolvidos nessa pesquisa, de modo que os dados foram retirados dos questionários respondidos por eles mesmos. Responderam ao questionário 11 professores de Português de três escolas da cidade de UberabaMG, no qual lhes foi solicitado que, em folha própria, fornecessem informações adicionais sobre idade, gênero, curso de habilitação profissional, tempo de formando, tempo de exercício de magistério e atuação profissional. Esse quadro nos possibilitará entender algumas respostas dadas por eles que serão apresentadas na próxima seção.

Tabela I: perfil dos participantes da pesquisa

\begin{tabular}{cc}
\hline & Professores (TOTAL $=\mathbf{1 1}$ respondentes) \\
\hline Gênero Masculino & $1 / 11=9,09 \%$ \\
\hline Gênero Feminino & $10 / 11=90,09 \%$ \\
\hline Ano de conclusão da graduação & \\
Entre 1980 e $\mathbf{1 9 9 0}$ & $1 / 11=9,09 \%$ \\
Entre 1991 e 2000 & $1 / 11=9,09 \%$ \\
Entre 2001 e 2010 & $5 / 11=45,45 \%$ \\
Entre 2011 e 2017 & $3 / 11=27,27 \%$ \\
Não quiseram responder & $1 / 11=9,09 \%$ \\
\hline Graduação em Universidade Pública & $4 / 11=36,36 \%$ \\
\hline Graduação em Universidade Particular & $6 / 11=54,54 \%$ \\
\hline Especialização & $8 / 10=72,7 \%$ \\
\hline
\end{tabular}




\begin{tabular}{cc}
\hline Especialização na área de linguagem & $2 / 11=18,1 \%$ \\
\hline Mestrado & $3 / 11=27,2 \%$ \\
\hline Tempo atuando como professor de LP & \\
Entre $\mathbf{2}$ a $\mathbf{1 0}$ anos & $3 / 11=27,2 \%$ \\
Entre $\mathbf{1 1}$ e $\mathbf{2 0}$ anos & $6 / 11=54,5 \%$ \\
Entre $\mathbf{2 1}$ e $\mathbf{2 8}$ anos & $1 / 11=9,09 \%$ \\
Não quiseram responder & $1 / 11=9,09 \%$ \\
\hline Já lecionaram outras disciplinas & $8 / 11=72,7 \%$ \\
\hline
\end{tabular}

Fonte: as autoras.

Esse quadro demonstra, em uma análise geral, que:

- O sexo preponderante é o feminino (90,09\%);

- A maioria dos professores formou-se entre os anos de 2000 e 2010, ou seja, tem mais de sete anos de formados;

- Poucos professores têm especialização na área de linguagem $(18,1 \%)$ e mestrado $(27,2 \%)$;

- A maior parte dos professores atua como professores de Língua Portuguesa por mais de 10 anos;

- Muitos professores já lecionaram outras disciplinas além da "língua portuguesa", entre elas: espanhol, inglês e artes.

\subsection{Avaliações linguísticas dos professores}

As reflexões feitas anteriormente demonstram a importância e a necessidade de um ensino reflexivo de língua materna nas escolas. Apesar de constatar que é possível e satisfatório uma prática pedagógica amparada a uma pedagogia culturalmente sensível, estamos, ainda, distantes desse ensino e isso acontece, principalmente, pela crença social sobre a língua, presente em todas as instâncias da sociedade, que contribui para a manutenção do ensino tradicional pautado na "norma-padrão". Essa ideologia do padrão desvaloriza toda e qualquer realização linguística que não está presente nas prescrições da língua consideradas "corretas". Como exemplo disso, podemos citar respostas dos professores, extraídas dos questionários, que estão ligadas a noção de "certo vs. errado":

(01) Sim. verifica-se o predomínio da linguagem correta (autor 1) [...]

(02) Sim. A linguagem correta. 
Os professores, nos exemplos acima, estavam respondendo à questão número 2 do teste: "É possível ver diferenças entre os dois trechos? Aponte algumas". Nota-se que os professores consideraram o primeiro trecho pertencente à "linguagem correta", fazendo um julgamento dos recursos linguísticos empregados no segundo trecho, considerando-os como "errados". As crenças de que há uma língua correta exerce grande influência nas atitudes dos sujeitos e são manifestadas, como podemos ver nesse questionário. Ao dizer que os recursos utilizados pelo aluno do segundo trecho estão "errados", corrobora para que os alunos desacreditem de seu desempenho linguístico e construam crenças de que a língua portuguesa é muito difícil ou de que não sabem português. Cabe mencionar que o segundo trecho é aquele que apresenta ausência de CV, considerada, portanto, uma forma "errada".

A afirmação feita inicialmente neste capítulo pode ser atestada a partir do teste de atitudes realizada em uma das questões, no qual buscou identificar e comparar as atitudes subjetivas dos professores diante de dois trechos distintos (em que um não há marcação do morfema de plural), para verificar como esses professores percebem a variedade linguística que a escola impõe como modelo ideal. Para analisarmos as respostas obtidas a partir dessa questão, tivemos que considerar a análise quantitativa e qualitativa. Abaixo seguem os gráficos que apresentam a comparação entre as médias de todos os adjetivos, atribuídas pelos professores aos autores dos dois fragmentos:

Gráfico 1: médias de notas atribuídas ao autor do Trecho 1

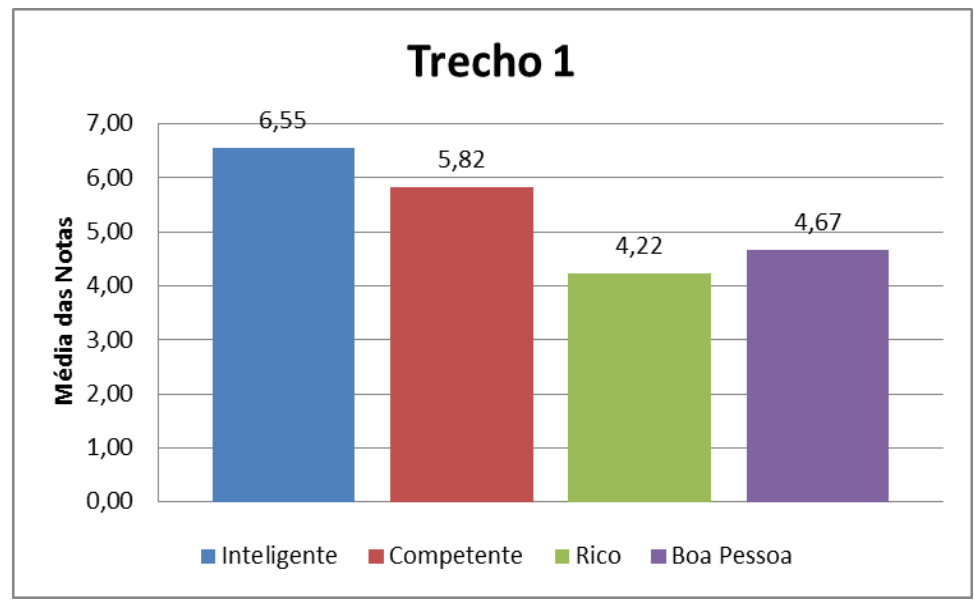

Fonte: as autoras 
Gráfico 2: médias de notas atribuídas ao autor do Trecho 1

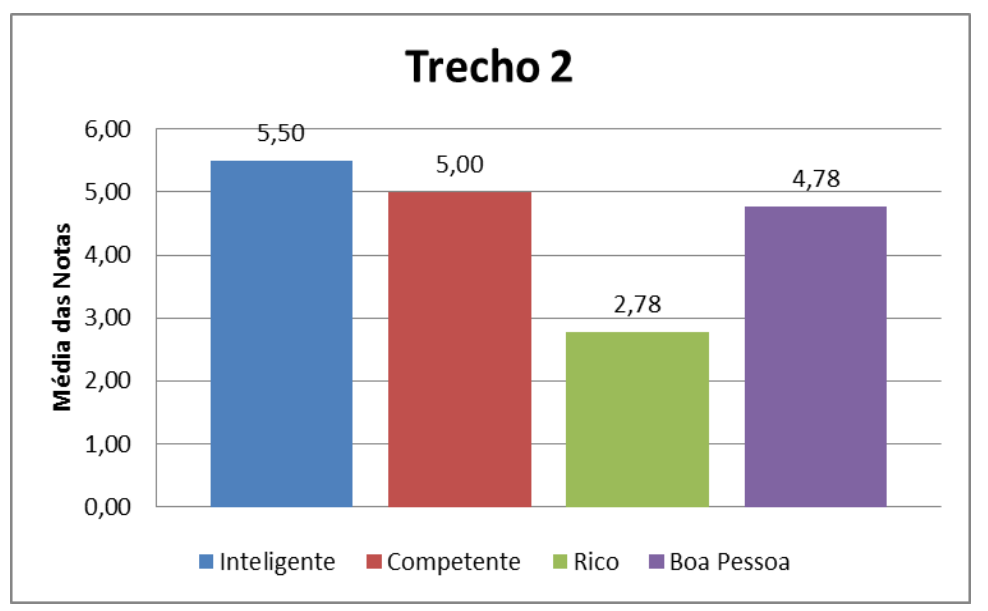

Fonte: as autoras

O gráfico 1 representa as médias dos adjetivos atribuídas ao fragmento que está de acordo com as regras previstas pela gramática normativa, de modo que não há desvios gramaticais, enquanto o gráfico 2 revela as médias atribuídas ao fragmento que há ausência de concordância verbal de $3^{\circ}$ pessoa do plural. Ao observamos os dois gráficos simultaneamente, podemos verificar que as maiores notas se relacionam aos adjetivos "Competente" e "Inteligente", no entanto, ao comparar um gráfico com o outro, é possível perceber uma queda da média no Gráfico 2. Houve uma queda de 1,05 para o adjetivo "Inteligente" e de 0,85 para o adjetivo "Competente", ou seja, houve mudanças de atitudes ao compararmos um fragmento com o outro.

O adjetivo que possuiu maior discrepância de notas ao compararmos os gráficos foi o adjetivo "Rico". O autor do primeiro trecho recebeu, em média, a nota 4,22 e o autor do segundo trecho recebeu a nota 2,78, diferença, em pontos, de 1,44. Essa diferença de resultados aponta uma aproximação do primeiro fragmento à norma culta, pois consideram aqueles que escrevem conforme a norma culta (com usos que tenham presença da CV) como +inteligente, +competentes e +ricos. Como defende Botassini (2015), quaisquer diferenças em seus julgamentos sobre a personalidade dos falantes representariam atitudes estereotipadas em relação aos membros de um grupo etnolinguístico específico.

O último adjetivo, que pertence a dimensão de solidariedade, possuiu a menor diferença, em pontos, ao se comparar os dois trechos, de modo que o trecho que há ausência de concordância verbal recebeu a maior nota: Trecho I com 4,67 e Trecho II com 4,7. 
Esses resultados corroboram com a afirmação de Chambers (1995), de que os sujeitos, em um teste de atitudes, atribuiriam as avaliações mais altas para as qualidades da dimensão de poder aos falantes da variedade padrão, enquanto que, ao contrário, os sujeitos atribuiriam as avaliações mais altas para as qualidades da dimensão de poder aos falantes regionais ou de outras variedades não-padrão. A análise das atitudes sugere haver uma identificação dos professores com a variedade de prestígio, uma vez que essa identificação é movida pelas dimensões de poder, no qual se consolida em nossa sociedade, com isso, os professores tendem a avaliar as variantes não padrão de forma negativa.

Para finalizar a análise, foi interessante notar nas respostas dos professores uma mudança de postura. Os resultados acima demonstram uma diferença de valor atribuídas as formas linguísticas presentes nos fragmentos, ou seja, um movimento do professor em enfatizar e contribuir com o imaginário de uma língua "pura", "correta", porém ao observar outras respostas, foi possível perceber um conhecimento mínimo sobre variação linguística. Seguem abaixo alguns exemplos:

(03) Provavelmente são escritos por pessoas diferentes pela linguagem empregada. Porém, pode ser que o mesmo autor tenha escrito as duas passagens em contextos diferentes, a fim de obter efeito de sentido variados.

(04) Não diria por pessoas diferentes, mas em situações comunicativas diferentes. [PE]

É possível observar nos exemplos acima, que os professores consideram, ao explicar sua resposta, a "adequação a diferentes contextos de comunicação" e que, assim, os trechos poderiam ser escritos pelas mesmas pessoas. O professor, portanto, defendendo essas observações no texto de um aluno, estaria, nesse caso, não vendo os dialetos sociais estigmatizados, mas um sistema linguístico capaz de oferecer os mesmos recursos expressivos utilizados na norma culta, não reprimindo o uso da variedade trazida pelo aluno de seu ambiente familiar. (CYRANKA, 2007, p.67). Sob a perspectiva da Sociolinguística, pode haver a concorrência de duas variantes para um mesmo fenômeno, sendo assim possível utilizar de duas maneiras uma mesma ocorrência. É o caso da concordância verbal, em que, de acordo com o contexto linguístico ou social, podemos utilizar preferencialmente uma variante ou outra.

Diferentemente dessas observações, o informante da citação abaixo transcrita, não considerou os trechos sendo escritos por pessoas diferentes em razão dos recursos linguísticos empregados, mas sim pelo fato de apresentarem conteúdos informacionais distintos. Ou seja, 
nenhum recurso linguístico utilizado foi "julgado", nem a ausência de CV, presente no trecho II. Vejamos o fragmento:

(5) Sim. Quando o autor 1 mostra que os personagens puderam conhecer culturas diferentes ele mostra que tem maior conhecimento de mundo em relação ao dois. [PB]

É animador essa atitude dos professores perante um texto que apresente ausência de $\mathrm{CV}$, apontando que talvez esses professores já estejam começando a recusar a ideologia do certo e do errado em língua, em favor da adequação ao uso, segundo as condições de produção. Esse aspecto positivo das avaliações dos professores pode estar relacionado com os resultados que observamos na Tabela I, que aponta o perfil dos professores da pesquisa. A maioria dos professores entrevistados formou-se entre os anos de 2001 e 2017, visto que a grade dos cursos de Letras nesses últimos anos possui um enfoque mais linguístico do que gramatical. De acordo com Barbosa (2015), há mais ou menos duas décadas, os cursos de graduação em Letras experimentam diversas publicações conscientizadoras do quanto o preconceito linguístico existe em nossa sociedade e o quanto o trabalho com a variação linguística é fundamental.

Há muito o que ser feito, pois ainda não conseguimos construir uma pedagogia culturalmente sensível à variação linguística adequada a essa área em nossas escolas. O cenário do ensino de língua precisa estar totalmente mudado para evitar preconceitos linguísticos. Com esse trabalho, buscamos um ensino de língua mais moderno, democrático crítico e reflexivo, para isso o professor (e também toda a sociedade) deve possuir contato com autores que tratam sobre a variação linguística e seu impacto no ambiente escolar e estar aberto a uma nova concepção de língua. Defendemos que os professores devem estar em formação continuada, buscando mais conhecimento e aperfeiçoando suas práticas pedagógicas com base em uma reflexão linguística.

\section{Considerações finais}

O teste de atitude, amparada à técnica do diferencial semântico, possibilitou observar a exteriorização do que o professor pensa em relação ao uso da CV. O teste demonstrou a aproximação do professor às convenções e aos padrões institucionalizados, corroborando com as pesquisas que envolvem esse fenômeno variável: a não realização do traço morfológico de número possui um valor sociolinguístico e uma maneira de desqualificar o falante da língua.

As médias das notas atribuídas aos autores dos fragmentos demonstraram que há 
imagens e significações que recobrem a língua e é reforçado por todas as instâncias da sociedade, inclusive a escola. Esse imaginário de hierarquização de um padrão, que cria estereótipos, está dentro de sala de aula e no imaginário dos professores.

A avaliação positiva das variedades de prestígio, em oposição às não prestigiadas, como se viu, tem consequências pedagógicas importantes. Os alunos não possuem uma boa experiência com a disciplina de Língua Portuguesa dentro de sala de aula, pois veem nela uma disciplina difícil. A dificuldade dos alunos frente a essa disciplina, diz respeito a prática docente, que limita o seu ensino a regras e nomenclaturas. Esse tipo de prática não faz do aluno um ser "pensante", que reflete sobre sua própria língua e possui a chave para perceber as diferenças de valor social entre as variantes linguísticas e, depois, saber tirar vantagem dessa habilidade sabendo selecionar a mais adequada conforme as exigências do contexto em que se encontra (FARACO, 2011, p.261), mas vê o aluno como um ser vazio, em que todo conteúdo deve ser depositado em sua mente.

O raciocínio que sustenta uma pedagogia da língua pautada em um ensino que não precise erradicar as variedades não-padrão é visto pela sociedade como um afronte à beleza e pureza da Língua Portuguesa, portanto temos um caminho árduo pela frente, já que a sociedade, em um todo, aceitou a hierarquização social das normas como ela está dada.

\section{Referências}

AMARAL, Ana Maria Guimarães. Reações subjetivas de professores de português ao dialeto não-padrão. 1989. Dissertação (Mestrado em Linguística) - Universidade de Brasília, Brasília.

BARCELOS, Ana Maria Ferreira. Reflexões acerca da mudança de crenças sobre ensino e aprendizagem de línguas. Revista Brasileira de Linguística Aplicada, Belo Horizonte, v. 7, n. 2, p. 109-138, 2007.

BORTONI- RICARDO, Stella Maris. Educação em língua materna: a sociolinguística na sala de aula. São Paulo: Parábola, 2004.

BORTONI- RICARDO, Stella Maris. Manual de Sociolinguística. São Paulo: Editora Contexto, 2014.

BOTASSINI, Jacqueline Ortelan Maia. A importância dos Estudos de Crenças e Atitudes para a Sociolinguística. Signum: Estud. Ling., Londrina, 2015, p.3-8.

BRASIL. Ministério da Educação e do desporto. Parâmetros Curriculares Nacionais de Língua Portuguesa $3^{\circ}$ e $4^{\circ}$ ciclos. Brasília, 1998.

CAMACHO, Roberto Gomes. Sociolinguística. In: BENTES, Ana Cristina; MUSSALIM, Fernanda. (org.) Introdução à linguística: domínios e fronteiras. vol.1. São Paulo: Cortez, 2001.

CARDOSO, Caroline Rodrigues; COBUCCI, Paula. Concordância de número no português brasileiro. In: BORTONI-RICARDO, Stella Maris; SOUZA, Rosineide Magalhães; (org.). Por que a escola não ensina gramática assim?. São Paulo: Parábola Editorial, 2014. 
CONDE SILVESTRE, Juan Camilo. Sociolinguística Histórica. Madrid: Editorial Gredos, 2007.

CYRANKA, Lúcia Furtado de Mendonça. A pedagogia da variação linguística é possível? In: ZILLES, Ana Maria Stahl; FARACO, Carlos Alberto; (Orgs). Pedagogia da variação linguística: língua, diversidade e ensino. Editora Parábora. São Paulo, 2015, p. 31-51.

CYRANKA, Lúcia Furtado de Mendonça. Atitudes linguísticas de alunos de escolas públicas de juiz de fora - mg. (Tese de doutorado). Universidade Federal Fluminense. Niterói, 2007.

ERICKSON, Frederick. Transformation and School Success: the Politics and Culture of Educational Achievement. Anthropology \& Education Quarterly. 1987, vol 18, n 4, p. 335-56.

FARACO, Carlos Alberto. Norma culta brasileira: construção e ensino. In: ZILLES, Ana Maria Stahl; FARACO, Carlos Alberto; (Orgs). Pedagogia da variação linguística: língua, diversidade e ensino. Editora Parábola. São Paulo, 2015.

FARACO, Carlos Alberto. Norma culta brasileira: Desatando alguns nós. São Paulo: Parábola, 2008.

FARACO, Carlos Alberto. Por uma pedagogia da variação linguística. In: CORREA, D. A. A relevância social da linguística: linguagem, teoria e ensino. São Paulo: Parábola; Ponta Grossa: UEPG, 2007.

FREIRE, Paulo. Medo e ousadia: o cotidiano do professor. São Paulo: Paz e Terra, 2011.

GNERRE, Maurizzio. Linguagem, escrita e poder. 4. ed. São Paulo: Martins Fontes, 1998.

LABOV, Willian. Padrões Sociolinguísticos. São Paulo: Parábola Editorial, 2008[1972].

LAMBERT, Wallace. A social psychology of bilingualism. Journal of social issues, Wiley Online Library, v. 23, n. 2, p. 91-109, 1967.

LAMBERT, Wallace. et al. Evaluational reactions to spoken languages. The Journal of Abnormal and Social Psychology, American Psychological Association, v. 60, n. 1, p. 44, 1960.

LUCCHESI, Dante; BAXTER, Alan; SILVA, Jorge Augusto Alves. A concordância verbal. In: LUCCHESI, Dante; BAXTER, Alan.; RIBEIRO, Ilza. (Orgs.). O português afro-brasileiro. Salvador: EDUFBA, 2009.

LUFT, Celso Pedro. Língua e liberdade. São Paulo: Ática, 2002.

MARINE, Talita.; BARBOSA, Juliana. Em Busca de um Ensino Sociolinguístico de Língua Portuguesa no Brasil. SIGNUM: Estud. Ling. Londrina, 2016, p.185-215.

MILROY, James. Ideologias linguísticas e as consequências da padronização In: LAGARES, Xoán Carlos; BAGNO, Marcos. Políticas da norma e conflitos linguísticos. São Paulo: Parábola, 2011. p. 49-87.

OLIVEIRA, Marian dos Santos. Concordância verbal de terceira pessoa do plural em Vitória da Conquista: variação estável ou mudança em progresso? Dissertação (Mestrado em Letras e Linguística) - Universidade Federal da Bahia. Salvador, 2005.

OSGOOD, Charles; SUCl, George; TANNENBAUM, Percy. The Measurement of meaning. Illinois: University of Illinois Press, 1957.

SANTOS, Emmanoel. Certo ou errado? Atitudes e crenças no ensino da língua portuguesa. Rio de Janeiro: Graphia, 1996.

SAUSSURE, Ferdinand. Curso de Linguística Geral. Editora Cultrix, 2006 [1916]. 
SCHERRE, Maria Marta Pereira.; NARO, A. J. Mudança sem mudança: a concordância de número no português brasileiro. In: SCRIPTA; Belo Horizonte, v.9. n.18. p. 107-129, $1^{\circ}$ sem. 2006.

SCHERRE, Maria. Marta. Pereira. Doa-se lindos filhotes de poodle: variação linguística, mídia e preconceito. - São Paulo: Parábola Editorial, 2005. (Lingua[gem]; 12).

VIEIRA, Silvia Rodrigues. Concordância verbal: variação em dialetos populares no norte fluminense. Rio de Janeiro, 1995. Dissertação (Mestrado) - Faculdade de Letras, Universidade Federal do Rio de Janeiro.

WEINREICH, Uriel; LABOV, Willian.; HERZOG, Marvin. Fundamentos empíricos para uma teoria da mudança linguística. Tradução Marcos Bagno. São Paulo: Parábola Editorial, 2006.

Recebido em 05/10/2019 e aprovado em 22/11/2019. 